\title{
TEACHING WRITING SKILL ON RECOUNT TEXT BASED ON BRAINSTORMING IN THE CLASSROOM
}

\author{
Suhaimi \\ Dosen STMIK Indonesia Padang \\ Korespondensi: Jalan Khatib Sulaiman Dalam No. 1, Lolong Belanti, Padang Utara, Kota Padang, \\ Sumatera Barat 25173
}

\begin{abstract}
The purpose of this article is to explain how to teach recount text in the classroom. The ability to write is one of the skills that should be taught in schools. Reality shows that there are many students who have problems in writing. The problems could be some students have limited ideas in writing. Furthermore, almost all of the students thought writing was boring, so they are not interested in writing. Then, writing is a difficult thing because they have to think about the selection of tenses and vocabulary correctly in a sentence. Considing facts, the author is interested in the theme of teaching the recount text-based brainstorming as one effective way to improve students' understanding in writing recount text. Brainstorming can increase students, creativity and to generate a lot of ideas in a short time, by extending the viewpoint of any aspects or thought .
\end{abstract}

Keyword: writing, recount text, brainstorming

\section{PENDAHULUAN}

$\mathrm{K}$ eterampilan menulis merupakan salah satu aspek keterampilan berbahasa yang harus dikuasai siswa, selain ketiga keterampilan lain yaitu menyimak, berbicara, dan membaca. Pembelajaran menulis di SD diberikan melalui mata pelajaran Bahasa Indonesia. Menurut pendapat Pelly (Haryadi dan Zamzani, 1996: 75), meskipun pembelajaran menulis telah disadari merupakan bagian penting dalam pembelajaran Bahasa Indonesia di $\mathrm{SD}$, namun pada kenyataannya pembelajaran menulis kurang mendapat perhatian dari guru maupun siswa.

Pembelajaran menulis atau mengarang kurang ditangani secara sungguhsungguh, sehingga keterampilan menulis yang dimiliki siswa kurang memadai. Keterampilan menulis sangat penting untuk dikuasai peserta didik. Keterampilan menulis akan banyak memberikan manfaat dalam kehidupan yang serba maju sekarang ini.

Menulis merupakan suatu kegiatan yang penting untuk dapat menuangkan isi pikiran, gagasan atau pendapat, ide maupun perasaan seseorang. Menurut Sabarti Akhadiah (1991: 111), kemampuan menulis didapatkan bukan melalui warisan, tetapi didapatkan melalui proses belajar mengajar. Keterampilan menulis dapat dimiliki oleh semua siswa jika mereka mendapat bimbingan dan latihan menulis secara intensif. Selain itu, peran guru juga sangat penting dalam melatih dan membimbing siswa menulis karangan dengan baik. Perbaikan dan umpan balik dari guru juga sangat diperlukan agar setiap kesalahan maupun kesulitan yang dihadapi siswa dapat 
diatasi, sehingga keterampilan menulis karangan siswa dapat meningkat. Seorang guru seharusnya mampu merangsang daya pikir dan kreatifitas peserta didik dalam mengekspresikan perasaan dan pendapatnya baik secara lisan maupun tertulis.

Dari paparan di atas, sudah terlihat jelas bahwa diharapkan kita sebagai seorang guru wajib memiliki keterampilan menulis, agar kelak dapat memberikan pengetahuan tentang keterampilan menulis yang baik kepada peserta didik. Dengan demikian, artikel ini disusun dengan tujuan agar kita lebih memahami materi mengenai keterampilan menulis dan dapat mengaplikasikannya didalam kehidupan nyata

\section{KAJIAN TEORI}

\section{Pengertian Menulis}

Menurut Akhadiah dkk (1998:1.3) menulis adalah suatu aktivitas bahasa yang menggunakan tulisan sebagai mediumnya. Tulisan itu sendiri atas rangkaian huruf yang bermakna dengan segala kelengkapan lambang tulisan seperti ejaan dan pungtuasi. Menulis sebagai suatu kegiatan penyampaian pesan mengandung makna bahwa menulis merupakan salah satu bentuk komunikasi verbal (bahasa). Pesan adalah isi atau muatan yang terkandung dalam suatu tulisan. Adapun tulisan merupakan sebuah sistem komunikasi antar manusia yang menggunakan simbol atau lambang bahasa yang dapat dilihat dan disepakati pemakainya. Di dalam komunikasi tertulis terdapat empat unsur yang terlibat. Keempat unsur itu adalah (1) penulis sebagai penyampai pesan, (2) pesan atu isi tulisan, (3) saluran atau medium tulisan, dan (4) pembaca sebagai penerima pesan.

Pernyataan Akhadiah di atas, pada hakikatnya menyatakan bahwa menulis adalah keseluruhan rangkaian kegiatan seseorang dalam mengungkapkan gagasan dan menyampaikannya melalui bahasa tulis kepada pembaca seperti yang dimaksud oleh pengarang. Agar komunikasi lewat lambang tulis dapat tercapai seperti yang diharapkan, penulis hendaklah menuangkan ide atau gagasannya kedalam bahasa yang tepat, teratur, dan lengkap. Dengan demikian, bahasa yang dipergunakan dalam menulis dapat menggambarkan suasana hati atai pikiran penulis. Sehingga dengan bahsa tulis seseorang akan dapat menuangkan isi hati dan pikiran.

Syafi'ie (1998: 45) menyatakan bahwa menulis adalah menuangkan gagasan, pendapat, perasaan, keinginan, dan kemauan, serta informasi ke dalam tulisan dan kemudian "mengirimkannya" kepada orang lain. Hal ini berarti menulis mengandung makna menyampaikan pikiran, perasaan, atau pertimbangan melalui tulisan. Alatnya adalah bahasa yang terdiri atas kata, frasa, klausa, kalimat, paragraf, dan wacana. Pikiran yang disampaikan kepada orang lain harus dinyatakan dengan kata yang mendukung makna secara tepat dan sesuai dengan apa yang ingin dinyatakan. Katakata itu harus disusun secara teratur dalam klausa dan kalimat agar orang dapat menangkap apa yang ingin disampaikan itu. Makin teratur bahasa yang digunakan, makin mudah orang menangkap pikiran yang disalurkan melalui bahasa itu. Oleh karena itu, keterampilan menulis di sekolah sangatlah penting.

Menulis pada hakikatnya adalah suatu proses berpikir yang teratur, sehingga apa yang ditulis mudah dipahami pembaca. Sebuah tulisan dikatakan baik apabila memiliki ciri-ciri, antara lain bermakna, jelas, bulat dan utuh, ekonomis, dan memenuhi kaidah gramatika. Kemampuan menulis adalah kemampuan seseorang untuk menuangkan buah pikiran, ide, gagasan, dengan memperguna- 
kan rangkaian bahasa tulis yang baik dan benar.

$$
\text { Sementara itu, WJS }
$$

Poerwodarminto (1987: 105) secara leksikal mengartikan bahwa menulis adalah melahirkan pikiran atau ide. Setiap tulisan harus mengandung makna sesuai dengan pikiran, perasaan, ide, dan emosi penulis yang disampaikan kepada pembaca untuk dipahami tepat seperti yang dimaksud penulis.

Kata keterampilan berbahasa mengandung dua asosiasi, yakni kompetensi dan performansi. Kompetensi mengacu pada pengetahuan konseptual tentang sistem dan kaidah kebahasan, sedangkan performansi merujuk pada kecakapan menggunakan sistem kaidah kebahasaan yang telah diketahui untuk berbagai tujuan penggunaan komunikasi. Seseorang dikatakan terampil menulis apabila ia memahami dan mengaplikasikan proses pegungkapan ide, gagasan, dan perasaan dalam bahasa Indonesia tulis dengan mempertimbangkan faktorfaktor antara lain ejaan dan tata bahasa, organisasi/susunan tulisan, keutuhan (koherensi), kepaduan (kohesi), tujuan, dan sasaran tulisan.

\section{Pengertian Teks}

Salah satu pendapat menyatakan bahwa pengertian dari teks adalah sebuah peristiwa komunikatif yang harus memenuhi beberapa syarat, yakni tujuh kriteria teks. Akan tetapi Renkema menyatakan bahwa beberapa dari kriteria tersebut bersifat subjektif dan tergantung pada pengamat tertentu. Konsekuensi jika menggunakan tujuh kriteria tersebut adalah tidak memberi kemungkinan terhadap perbedaan yang bisa diprediksi dan dihadirkan secara nyata dan ujaran apa saja pada dasarnya bisa dipandang sebagai teks dalam sebuah konteks tertentu.

Kriteria yang dimaksud pada pendapat de Beaugrande \& Dressler adalah kohesi-keterhubungan 'sintaksis teks' atau keterikatan antar unsur dalam struktur sintaksis atau struktur wacana yang ditandai antara lain dengan konjungsi, pengulangan, penyulihan, dan pelesapan (Pusat Bahasa, 2008: 712); koherensi-menyusun makna se-buah teks atau hubungan logis antara bagian karangan atau antara kalimat dalam satu paragraf (Pusat Bahasa, 2008: 712); intensionalitas-berhubungan dengan sikap dan tujuan produser teks; akseptabilitas-berkaitan dengan kesiapan pendengar dan pembaca untuk mengharapkan sebuah teks yang berguna atau relevan; informativitas--mengacu pada kuantitas informasi; situasional - konstelasi-pembicaraan dan situasi tuturan memainkan peran penting dalam pemroduksian teks; intertekstual--Teks hampir selalu terkait dengan wacana yang muncul sebelum atau bersamaan dan Ada yg menghubung-kan teks tertentu dg teks lain dalam genre atau jenis tertentu.

Analisis teks linguistik difokuskan pada kohesi dan koherensi wacana atau secara umum dapat disimpulkan bahwa fokus untuk anlisis teks linguistik mencakup tataran sintaktik, semantik, dan pragmatik. Dalam pandangan kritis teks dibangun dari sejumlah piranti linguistik untuk memberikan struktur linguistik dalam teks bahasa yang di dalamnya terdapat ideologi dan kekuasaan. Menurut Fairclough (dalam Darma, 2009: 72) tahap pemberian tersebut berupa analisis kosakata, gramatika, dan struktur teks.

Refleksi mengenai istilah wacana, menurut Van Dijk wacana hendaknya dipahami sebagai tindakan dengan cara memandang wacana umum sebagai teks dalam konteks. Ada juga yang berpendapat bahwa wacana berfungsi sebagai bentuk praktik sosial. Tarigan (dalam Darma, 2009: 2) menyebutkan bahwa wacana adalah satuan wacana terlengkap dan tertinggi atau terbesar di atas kalimat atau klausa dengan ko- 
herensi dan kohesi tinggi yang berkesinambungan, yang mempu mempunyai awal dan akhir yang nyata, disampaikan secara lisan atau tertulis.

Pengertian konteks dalam KBBI (2008: 728) adalah bagian suatu uraian atau kalimat yang dapat mendukung atau menambah kejelasan makna. Konteks dibagi menjadi konteks makro dan konteks mikro, konteks makro-dalam berbagai organisasi dan institusi, konteks mikro- wacana yang terjadi dalam waktu tertentu, tempat tertentu, partisipan tertentu dan sebagainya. Sedangkan Aaron Cicourel juga membagi menjadi dua bagian, yaitu konteks luas dan lokal. Djajasudarma (2010: 35) menyatakan bahwa rincian dalam konteks antara lain, rincian ciri luar (fisik), rincian emosional, rincian perbuatan, rincian campuran.

\section{Jenis-jenis Teks dalam Bahasa Inggris (Narrative, Report, Descriptive, Procedure)}

Dalam Bahasa Inggris terdapat macam-macam jenis teks. Di bawah ini adalah beberapa jenis teks yang harus diketahui dan dipahami oleh siswa SMP, berikut ini adalah 5 jenis teks beserta penjelasan sederhana dari teks tersebut:

\section{Descriptive}

Teks Descriptive adalah teks yang menggambarkan seseorang, benda atau tempat tertentu sehingga pembaca dapat membayangkan seolah-olah yang diceritakan itu benar-benar nyata.

Tujuan Komunikatif:

memberikan informasi mengenai ciri-ciri seseorang, benda atau tempat tertentu.

Struktur Teks:

a) Identification/Pengenalan: ciri-ciri seseorang, suatu benda atau tempat tertentu yang akan dideskripsikan.

b) Description/Deskripsi:

menggambarkan ciri-ciri seseorang, benda atau tempat tersebut, misalnya bentuk, ukuran, warna, asal, kegemaran dan ciri khusus lainnya.

\section{Narrative}

Teks Narative adalah teks yang bercerita mengikuti alur waktu.

Tujuan Komunikatif: Menghibur pendengar atau pembaca dengan pengalaman nyata atau khayal.

Ciri naratif adalah adanya unsur konflik (masalah) dan resolusi (penyelesaian masalah).

Struktur Teks:

a) Pengenalan latar: tokoh, waktu, dan tempat.

b) Pengembangan konflik.

c) Penyelesaian konflik.

d) Koda: perubahan yang terjadi pada tokoh atau pelajaran yang dapat dipetik dari cerita.

\section{Generic Structure Narrative Text}

Setiap jenis teks bahasa Inggris (genre) memiliki struktur teksnya sendiri-sendiri. Struktur dari Narrative Text terdiri dari tiga bagian yaitu:

a) Orientation: Pada bagian Orientation atau pengenalan berisi tentang pengenalan tokoh dalam cerita serta waktu dan tempat kejadiannya.

b) Complication: Pada bagian Complication berisi tentang gambaran munculnya krisis atau masalah yang di alami oleh tokoh pada cerita tersebut yang harus dipecahkan.

c) Resolution: Pada bagian Resolution berisi tentang bagaiman tokoh dari cerita tersebut memecahkan masalah yang ada pada bagian Complication. Biasanya terdapat lebih dari satu Resolution untuk satu Complication.

Pada beberapa referensi tentang Narrative Text, terdapat tambahan generic structure pada Narrative Text, yaitu penambahan Code setelah Resoultion. Jadi susunan Narrative text adalah Orientiation, Complication, Resolution dan Coda. 
Coda adalah bagian terakhir dari structure Narrative Text yang berisi perubahan yang terjadi pada tokoh dan pelajaran yang dapat dipetik dari cerita tersebut.

\section{Procedure}

Teks Prosedure adalah teks yang menjelaskan dengan jelas cara membuat atau melakukan sesuatu.

Tujuan komunikatif:

Memberi petunjuk cara melakukan sesuatu melalui serangkaian tindakan atau langkah.

Struktur Teks: Goal/Aim/TujuanMaterials/Tools/Bahan/Alat-

Steps/Methods/Langkah

Generic Sturcture Procedure Text

\section{Aim/ Goal}

Pada generic sturcture bagian pertama dari Procdeure Text ini berisi informasi mengenai tujuan dalam pembuatan atau pengoprasian sesuatu.

\section{Materials}

Pada bagian kedua, Materials teridiri dari bahan-bahan yang digunakan dalam membuat sesuatu. Tapi tidak semua Procedure Text menyertakan bagian materials, adakalanya sebuah Procedure text tidak memiliki bagian materials.

Ada tiga jenis procedural text yang tidak menggunakan bagian materials, yaitu:

a) Procedural text yang menjelasakan bagiamana sesuatu bekerja atau bagaimana cara melakukan instruksi secara manual. Contohnya: How to use the video game, the computer, the tape recorder, the fax, etc.

b) Procedural text yang menginsturksikan bagaimana melakukan aktivitasaktivitas tertentu dengan peraturanya. Contohnya: raod safety rules, video game rules, etc.

c) Procedural text yang berhubungan dengan sifat atau kebaiasaan manusia.
Contohnya How to live happily, How to secceed.

\section{Recount}

Teks Recount adalah teks yang menceritakan kembali kejadian yang telah terjadi berurutan dengan menggunakan keterangan waktu yang jelas pada masa lampau

Tujuan komunikatif:

Melaporkan peristiwa, kejadian atau kegiatan dengan tujuan memberitakan atau menghibur.

Struktur teks:

a) Orientation: Pendahuluan yaitu memberikan informasi orang atau benda yang melakukan atau yang terlibat di dalamnya, serta waktu, tempat, situasi, dan lain-lain;

b) Event 1, Even 2...: Rangkaian peristiwa yang terjadi, yang biasanya disampaikan secara urut.

c) Re-orientation: Kesimpulan dari rangkaian peristiwa yang terjadi. Reorientation tidak selalu ada pada teks recount.

d) Generic structure Teks Recount

Orientation

Orientation atau pengenalan yaitu memberikan informasi tentang siapa, dimana, dan kapan peristiwa atau kegiatan itu terjadi di masa lampau.

Events

Events merupakan rekaman peristiwa yang terjadi, yang biasanya disampaikan dalam urutan kronologis, seperti "In the first day, I ... . And in the next day... . And In the last day ...". Di bagian events ini juga biasanya terdapat komentar pribadi tentang peristiwa atau kejadian yang diceritakan.

\section{Reorientation}

Pada bagian reorientation, terdapat pengulangan pengenalan yang ada di orientation, pengulangan yang merang- 
kum rentetan peristiwa, kejadian atau kegiatan yang diceritakan.

\section{Report}

Teks Report memiliki kemiripan dengan teks deskriptif, teks report memberikan gambaran umum tentang sesuatu tidak mendetail seperti pada teks Deskriptif.

Tujuan Komunikatif: Menyampaikan informasi tentang sesuatu, apa adanya, sebagai hasil pengamatan sistematis atau analisis.

Stuktur Teks:

a) General Classification: (klasifikasi umum, yaitu menggolongkan atau menentukan secara umum termasuk kepada golongan mana.

b) Description: yaitu uraian deskripsi atau gambarannya bagia-bagian yang umum ada padanya, derajatnya, dam sifat-sifatnya. Biasanya berupa uraian umum.

Struktur Teks/Generic structure Report Text

Dalam Report Text, terdapat struktur teks yang terdiri dari dua bagian, yaitu:

\section{General Clasification}

Pada bagian general clasification (klasifikasi umum) berisi pengenalan fenomena/ benda yang akan dibicarakan dengan menyertakan pernyataan umum yang menerangkan subjek laporan, keterangan, dan klasifikasi-nya.

\section{Description}

Pada bagian Description (gambaran) terdiri dari gambaran dari fenomena/ benda yang didiskusikan dari bagian ke bagiannya, kebiasaan atau tingkah laku untuk benda hidup, ataupun kegunaannya untuk benda secara detail.

\section{Text recount}

Salah satu teks yang diajarkan di kelas adalah RECOUNT. Teks ini pada umumnya menyampaikan pengalaman yang telah dilalui oleh seseorang. Penyampainya dapat si pelaku itu sendiri, atau sebaliknya seseorang menyampaikan pengalaman orang lain. Teks recount adalah jenis teks yang menguraikan atau menceritakan kejadian atau peristiwa yang telah lewat, misalnya kecelakaan, laporan kegiatan, kunjungan ke suatu tempat, atau pengalaman lainnya.

\section{Writing dalam Text Recount}

Jenis teks Recount yang sudah dikenal oleh para siswa adalah Diary, yakni tulisan yang berisi curahan perasaan yang dialami pada suatu hari. Recount yang lain adalah Biografi dan autobiografi

Ketika para siswa diminta menuliskan teks berbentuk recount, setelah mereka diberi penjelasan dan contoh, ciri gramatik dan ciri bahasa dalam teks ini, para siswa mengalami kesulitan sebagai berikut:

Memulai Orientation, sekalipun telah dijelaskan bahwa pada orientation harus memuat Who, What, When dan Where, atau ada Opening, beberapa menit dihabiskan hanya untuk menentukan Orientation.

Tidak menggunakan Past tense. Para siswa tetap menggunakan Present untuk menceritakan kejadian yang telah lewat.

Banyak meminta guru untuk menerjemahkan kata yang akan ditulisnya.

Menggunakan kata dengan mencaplok dari kamus, tanpa merujuk apakah kata tersebut kelompok noun, adjective, verb atau yang lainnya, sehingga kalimatnya menjadi rancu dalam makna.

Menuliskan teks secara lengkap dalam bahasa Indonesia terlebih dahulu, baru kemudian diterjemahkan. Pengubahan dari bahasa Indonesia menjadi bahasa Inggris menjadi semakin sulit karena ada beberapa kata yang tidak mereka temukan dalam kamus IndonesiaInggris.

Menggunakan bahasa terjemahan dari Alfa link

Kekurangan gagasan untuk dituangkan, sehingga ada siswa yang mengobrol

Kebingungan untuk menuliskan apa, dengan alasan mereka tidak tahu harus menuliskan apa

Penguasaan kosakata tidak memadai untuk mampu membuat sebuah teks yang padu. 
Waktu 60 menit, tidak cukup untuk membuat suatu tulisan yang memuat orientation, events, reorientation dan comment.

\section{PEMBAHASAN}

Langkah-langkah yang ditempuh oleh siswa dalam belajar keterampilan menulis recount text didalam kelas berbasis braintorming dapat dilakasanakan sebagai berikut;

1. Guru menyuruh siswa untuk membagi kelas menjadi beberapa kelompok

2. Guru memberikan tema tentang recount, misalkan temanya pengalaman siswa pergi jalan-jalan ke Bukittinggi ketika libur

3. Tema yang diberikan berbeda-beda pada tiap-tiap kelompok

4. Masing-kelompok melakukandiskusi dengan melakukan brainstorming untuk mengumpulkan kosa kata yang berkaitan dengan tema tersebut. Contoh:

On Sunday, Travelling,went, bus, took, get on, see, fare, tourism object, friend, teacher, prepare, food, clock tower,sianok Canyon, zoo, morning, afternoon, tired, happy, enjoy, school, shopping, etc.

5. Kemudian masing kelompok diarahkan oleh guru untuk membangun kalimat dengan menggunakan kosa kata yang telah terkumpul. Contoh

It was on Sunday

I went traveling to Bukittinggi

I took the bus

I got on the bus

We saw some scenerry

The scenerry is beautiful

We visited some tourism object in Bukittinggi

We went to Bukittinggi with our friend and teachers

We buy some food and drink

We went shopping

We were happy

We were tired

We came back home in the afternoon
Etc.

6. Langkah berikutnya guru menyuruh siswa dalam bentuk diskusi untuk menyusun kalimat diatas kedalam bentuk paragraf yang benar dengan menyusn kalimat itu secara runtut dan koheren, dimana ide dari paragraf tersebut tidak melmpat-lompat dan dapat dipahami dengan mudah. Guru juga mengarahkan serta membimbing siswa untuk memperkaya kalimat tersebut dengan kata yang lain seperti keterangan waktu, ket. Cara, tempat ,frequency dan kata transisi seperti firts, then, after that, as soon as, finally, ect contoh:

It was on Sunday, we and our Friend from school of Andalusia went travelling. We went to Bukittinggi. We took a tourist bus. The bus left at 8 o'clock from terminal and arrived at 10 o'cock. It took two hours to Bukitinggi from Padang, as soon as we arrived ,Firstly,we visited Clock Tower and played for a few minuts there then we walked to the zoo. Here we looked at some kinds of animals like tiger, lion, and some birds. They were cute and funny. We liked them very much.After lunch, we continued our visits to Sianok Canyon. It was not so far from the city. We took a few minuts to walked. We took a photo there. The scenery is beautiful. In the afternoon we came back home. We were very tired but we were happy

7. Langkah selanjutnya guru menuyuruh salah satu kelompok menuliskan hasil dari recount text mereka didepan kelas, kemudian guru mengoreksi tulisan tersebut seperti tanda baca, tenses, dan koheren dari kalimat dan seterusnya, kelompok yang lain disuruh oleh guru menyimak.

8. Langkah terakhir masing-masing grup disuruh memperbaiki hasil dari recount teks mereka dan kemudian diserahkan keapada guru untuk dinilai. 


\section{PENUTUP}

Menulis pada dasarnya merupakan suatu kegiatan yang produktif dan ekspresif. Untuk mengembangkan keterampilan menulis diperlukan langkahlangkah dan tahapan-tahapan. Pada pembelajaran menulis guru hendaknya mampu mengarahkan setiap tahapan menulis dengan baik dan tepat, sehingga siswa benar-benar paham dan tulisan yang dihasilakan baik. Guru juga harus pandai dalam memilih dan menggunakan pendekatan dalam proses pembelajaran menulis. Selain memilih pendekatan yang tepat, guru juga harus pandai memilih dan menggunakan media pembelajaran sehingga pembelajaran menulis dapat berjalan efektif. Baik siswa maupun guru hendaknya aktif dalam

\section{DAFTAR RUJUKAN}

Ahmadi, M. 1988. Materi Dasar Pengajaran Komposisi Bahasa Indonesia. Jakarta: Depdikbud.

Akhadiah, S., Maidar, G.A., dan Sakura, H.R. 1989. Pembinaan Kemampuan Menulis Bahasa Indonesia. Jakarta: Erlangga.

Departemen Pendidikan Nasional. 2008. Kamus Besar Bahasa

Indonesia: Pusat Bahasa. Jakarta: PT Gramedia

Haryadi dan Zamzami. 1996. Peningkatan Keterampilan Berbahasa Indonesia. Jakarta: Depdikbud Dikti

Keraf, G. 1997. Komposisi. Ende Flores Nusa Tenggara Timur: Nusa Indah.

Kosasih, E. 2002. Kompetensi Ketatabahasaan: Cermat Berbahasa mencari informasi atau ide-ide untuk menulis agar tulisan yang dibuat semakin berkembang. Dengan semakin berkembangnya tulisan yang dibuat maka keterampilan menulis siswa dapat meningkat secara signifikan.

Keberhasilan menulis ditentukan oleh banyak faktor begitu juga dengan keberhasilan pembelajaran menulis. Hal ini dikarenakan menulis bukanlah hal yang mudah dan merupakan suatu proses. Belajar teori menulis itu mudah, tetapi untuk mempraktikkannya tidak cukup sekali dua kali. Frekuensi latihan menulis akan menjadikan seseorang terampil dalam bidang tulis-menulis. Oleh karena itu, jika ingin berhasil dalam menulis maka harus sering berlatih, berlatih, dan berlatih.

Indonesia. Bandung: Yrama Widya.

Musaba, Z. 1994. Terampil Menulis dalam Bahasa Indonesia yang Benar. Banjarmasin: Sarjana Indonesia.

Soedjito dan Hasan, M. 1986. Seri Membina Keterampilan Menulis Paragraf. Malang: Tanpa Penerbit

Spandel, V. and Stigginis, R. J. 1990. Creating Writers. London: Longman.

Suparno. 2002. Keterampilan Dasar Menulis. Jakarta: DepdiknasUT

Syafi'ie, I. 1988. Retorika dalam Menulis. Jakarta: Depdikbud.

Tarigan, H.G. 1987. Menulis sebagai Suatu Keterampilan Berbahasa. Bandung: Angkasa. 